\title{
Proposed Framework for Measuring Enterprise Gamification Impact on Employees' Performance: ABANA Enterprises Group Company Case Study
}

\author{
Nora AlMadi ${ }^{1} \&$ Wafi AlBalawi ${ }^{2}$ \\ ${ }^{1}$ Graduate student at Management Information Systems Department, College of Business Adminsitration, King Saud \\ University, Saudi Arabia \\ ${ }^{2}$ Assistant Professor, Management Information Systems Department, College of Business Adminsitration, King \\ Saud University, Saudi Arabia \\ Correspondence: Wafi AlBalawi, Assistant Professor, Information Systems Department, College of Business \\ Adminsitration, King Saud University, Saudi Arabia.
}

Received: October 20, 2015

Accepted: November 12, 2015

Online Published: November 17, 2015

doi:10.5430/jms.v6n4p50

URL: http://dx.doi.org/10.5430/jms.v6n4p50

\begin{abstract}
Gamification is an emerging information system concept that only got popular in 2010 under the human computer interaction sciences. Gamification is rapidly growing thanks to its success in enhancing the user engagement and being positively changing user's behavior. After acknowledging its role, it has been utilized in different fields of business for both of their customers; the externals and internals (their employees). Previous studies have proved Gamification role in changing external customers' behavior and achieving the desirable objectives. Unfortunately, no clear results or models have been proved or standardized regarding the internal customers (the employees). The objective of this research is to explore the factors should be taken into consideration when developing or studying a Gamification application in order to enhance employees' performance.
\end{abstract}

Keywords: employee engagement, gamification, enterprise gamification, the lord of ABANA, ABANA Enterprises Group Co.

Methodology: This is an exploratory, short-term case study that studies ABANA Enterprises Group Company's gamified application ("The Lord of ABANA"), where three departments (HR, sales, and finance) have participated in the study. Surveys, observation, monitoring employees' performance digitally have been used.

Results: The results have delivered factors that should be taken into consideration when developing Gamification for employees, which have been expressed in a framework.

\section{Introduction}

In the recent years, the tremendous number of phenomenal technologies that emerged facilitated globalization and changed the world of business, as we know it. Businesses became more competitive against each other and seek to satisfy customers first by becoming more customer-focused. In order to achieve that, businesses acknowledged the importance of satisfying their first customers, their employees.

Therefore, a lot of new techniques and strategies have been introduced to facilitate employee engagement and motivate them, in order to satisfy them including Gamification. The term Gamification only came into widespread use in February 2010, as part of the DICE 2010 conference (Xu, 2012), where it has been introduced with the aim to engage users, both customers and employees in a fun and enjoyable environment and enhance their performance. Gamification has been hugely used in different fields including: education, health, e learning, mobile apps, user experience enhancement, customer service, and employee engagement. Although, Webb and Cantu (2013) have noted, "While the concept of using game mechanics to attract and retain customers in the consumer space is now well accepted, the use of Gamification in the enterprise space is still catching on". Furthermore, studies that have been done in this area have not agreed on neither positive nor negative effect toward engagement, as the review of Hamari, Koivisto, et al (2014) indicated. Moreover, no models or frameworks have been presented to measure the use of Gamification in enhancing employees' performance. 
Gamification applications in Saudi Arabia are mainly utilized in education and health applications. Therefore, utilizing it in business is still considered to be new, especially in the employee engagement area with no precise model that can be used to measure Gamification efficiency.

This paper aims to explore the factors and concepts that will be expressed in a conceptual framework, which should be taken into consideration when developing or Gamification impact on employees' performance by interviewing and monitoring the performance of the employees of HR, sales, and finance departments in ABANA Enterprises Group Co. during one-month period.

\subsection{The Research Problem}

In this competitive business world, enterprises are eager to success, while enterprises success depends on their employees and how much engaged they are. Therefore, motivating employees is a must to ensure their engagement. Motivation can be either intrinsic (beliefs, values, enjoyment, etc.) or extrinsic (salary, insurance, rewards, etc.). Businesses for decades have been focusing on the extrinsic motivations ignoring the intrinsic ones and their importance. Fortunately, businesses have started realizing the importance of the intrinsic motivations and their role in enhancing employees' engagement in the recent years in cost-effective manners.

Moreover, the rapid growth of technology have facilitated this mission for enterprises by introducing innovative and creative techniques that may help businesses in achieving this goal in order to improve work performance effectively and efficiently. Gamification is one of these fast emerging technologies that still covered with uncertainty when developing or studying it in the field of employee engagement.

Therefore, this research is trying to study the possibility of proposing a framework that will facilitate studying and measuring the impact of Gamification on employees' performance.

\subsection{The Purpose of the Study}

The intention and purpose of this research is to explore the factors and concepts that will be expressed in a conceptual framework, which should be taken into consideration when developing or studying Gamification impact on employees' performance by studying ABANA Enterprises Group Company experience with their gamified application with the aim to identify the relationships between the Gamification concept and these factors.

Moreover, the lack of researches in this field has given this research the importance to be done, so future researches can benefit from its collected data and results.

\subsection{Research Significance}

This study got its significant due to the following points:

- Gamification can resolve a numerous business issue related to employee engagement in order to produce a more efficient work.

- The willingness to adopt and use this kind of application can be noticed due to the big number of population who play games in Saudi Arabia.

- Gamification is considered to be one of the newest and trendy concepts in the Management Information System research area.

- This research will be handy for future researches about Gamification.

- Starting from its rise in 2010, Gamification utilization in general has became a great and huge interest to the researcher.

- Moreover, the magnificent help and support from ABANA Enterprises Group Co., which facilitated collecting data have increased this research significance.

\subsection{The Research Questions and Objectives}

This research will be discussing and achieving the following objectives:

- To identify the factors and concepts that should be measured when studying or developing a gamified system in order to enhance employees' performance.

- To create a conceptual framework for these factors.

- To explain the relationships between these factors and how it can affect the concept.

1.5 Definitions of Key Terms, Concepts and Variables

The following table contains the main terms that will be in this research: 
Table 1. Key terms

\begin{tabular}{|c|c|c|}
\hline Reference & Term & Definitions \\
\hline Webb and Cantu (2013) & $\begin{array}{l}\text { Employee } \\
\text { Engagement }\end{array}$ & $\begin{array}{l}\text { "The degree or extent to which employees feel committed to } \\
\text { their work and their organization" }\end{array}$ \\
\hline Gartner (2014) & Gamification & $\begin{array}{l}\text { "The use of game mechanics and experience design to digitally } \\
\text { engage and motivate people to achieve their goals". }\end{array}$ \\
\hline Gartner (2014) & $\begin{array}{l}\text { Game elements/ } \\
\text { mechanics }\end{array}$ & $\begin{array}{l}\text { "Game mechanics are the elements used in the resulted gamified } \\
\text { application (e.g. badges, points, etc.)." }\end{array}$ \\
\hline Hamari, Koivisto,et al (2014) & Game context & $\begin{array}{l}\text { "The business field that the Gamification has been used in, } \\
\text { including: e-commerce, education/learning, health/exercise, } \\
\text { intra-organizational systems, sharing, sustainable consumption, } \\
\text { work, innovation/ideation, and data gathering." }\end{array}$ \\
\hline \multirow[t]{3}{*}{ Kumar (2013) } & Enterprise & "Enterprise Gamification has become an emerging concept to \\
\hline & Gamification & $\begin{array}{l}\text { ensure user engagement through enterprise software and the } \\
\text { business processes in general in effective and efficient manners". }\end{array}$ \\
\hline & $\begin{array}{l}\text { The Lord } \\
\text { ABANA }\end{array}$ & $\begin{array}{l}\text { "The Lord of ABANA" application is a short-term online } \\
\text { application that has been developed with month duration to fill the } \\
\text { gaps and to enhance the employees" performance. }\end{array}$ \\
\hline
\end{tabular}

\section{Literature Review and Theoritical Framework}

The previous studies in the field of Gamification have emerged since 2010, starting with defining and introducing the concept to continue with its usage in different fields that are concerned with: customers and employees satisfaction, Education, Health, Awareness, etc. Moreover, they studied the impact of its usage in these different fields. Furthermore, previous studies included different approaches to conceptualize Gamification and providing best practices to be used. However, Gamification is considered to be a new field of study. Moreover, no clear or standard model or framework had been proposed.

\subsection{Gamification}

Even though the concept of Gamification has been represented in February 2010 (Rughiniş, 2013), people have experienced the concept decades ago. People have engaged through Gamification in their learning process, in different marketing campaigns and even in other services fields through their lives. They have experienced Gamification through badges, points they collect, the sticker behind the cereal box they eaten.

\subsubsection{Definition}

"Most definitions on Gamification we found in literature have three main elements. First, Gamification is a kind of games. It is characterized by the set of rules, a declarative content and the gameplay as well as a social context (Bree 2011)"

Deterding, Dixon, Khaled, et al (2011) defined Gamification as "the use of video game elements in non-gaming systems to improve user experience (UX) and user engagement". While a lot of researchers have agreed on this definition (Hall, Glanz, Caton, et al, 2013; Rughiniş, 2013; Webb, 2013; Hense, Klevers, Sailer, et al, 2014), Werbach (2014) have argued, "Gamification should be understood as a process. Specifically, it is the process of making activities more game-like." He clarified that identifying Gamification as process has its own benefits for academic and business fields, "creates a better fit between academic and practitioner perspectives." Moreover, he noted its role in focusing in the game part, "it focuses attention on the creation of game-like experiences, pushing against shallow approaches that can easily become manipulative." Finally, he added. "A final benefit of this approach is that it connects Gamification to persuasive design." Moreover, Game developers are not satisfied with the naming the concept Gamification" and have criticized that as Nicholson, S. (2012) clarified, "By putting the term "game" first, it implies that the entire activity will become an engaging experience, when, in reality, Gamification typically uses only the least interesting part of a game - the scoring system." Also, the important point about Gamification is to keep in mind that Gamification is not for a long-term impact, but it is only dedicated to short-term one, as Nicholson (2012) emphasized.

Another redefinition have been presented by Gartner (2014) to clarify the Gamification concept, as "the use of game mechanics and experience design to digitally engage and motivate people to achieve their goals", which is make the Gamification concept more specific, logical, and clearer than previous definitions. Gartner's definition contains of key elements, which are: 
- Game mechanics, which are the elements used in the resulted gamified application (e.g. badges, points, etc.).

- Game experience, which is the journey the users take (e.g. storyline, game play, etc.).

- Digitally engage, which means that user can engage and interact with the gamified application through different computers, smartphones, wearable technologies, tablets, etc.

- Motivate people, which the goal of Gamification and to change their behaviors or develop skills, or to drive innovation.

- Achieve their goals, when aligning business goals with Gamification, achieving them will be a consequence of utilizing Gamification.

\subsubsection{Usage/ Game Context}

Gamification has been used in different fields and for different goals to achieve them in more engaging and enjoyable environment. Meder, Plumbaum, \& Hopfgartner (2013) have mentioned that Gamification used in different fields, including: "enterprises workplaces, education, pervasive health care, e-commerce, human resource management and many more". In addition, Gamification has been used in commercial apps to increase user engagement (e.g. FourSquare) (Zeynep, Cramer, Holmquist, et al, 2011). Social networks (e.g. Facebook) use Gamification to motivate its users as well (Schacht, \& Schacht, 2012). Finally, Gamification has been used in "course design in university education, rehabilitation activities in the medical field, and e learning with the aim of maintaining and improving users' motives" (Otake, Sumita, Oka, et al, 2014).

However, Gamification is still considered a new and growing field and the attempts to use it is few so far, as Otake, Sumita, Oka, et al (2014) stated.

Hamari, Koivisto, et al (2014) in their paper have summarized the fields that use Gamification to include: e-commerce, education/learning, health/exercise, intra-organizational systems, sharing, sustainable consumption, work, innovation/ideation, and data gathering.

\subsubsection{Game Elements / Design and Frameworks}

Game Mechanics or design element answers the first part of the Gamification definition "using game elements in non-game context to improve user engagement" (Deterding, Dixon, Khaled, et al, 2011). So, what are these game elements that achieve the improvement of user engagement?

Werbach and Dan (2012) developed a framework that categorizes game elements into three categories and represented them in the "The Pyramid of Gamification Elements" (see Figure 1), as follows:

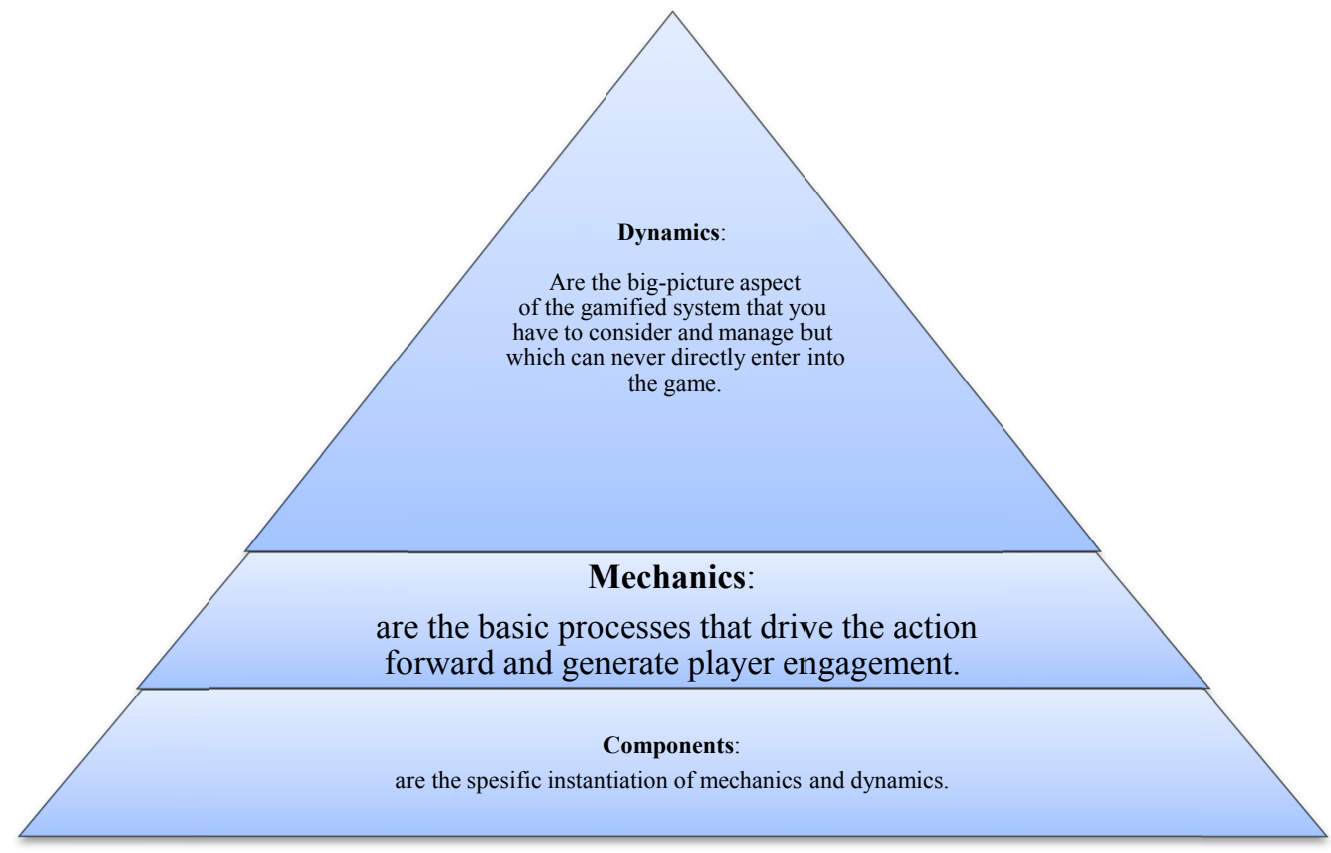

Figure 1. The pyramid of gamification (Werbrach and Dan, 2012) 


\section{Dynamics:}

According to Werbach and Dan (2012), dynamics are the big-picture of what should be consider into the gamified system. It is the large-scale objectives of the business, for instance: employee development, increasing sales profit, creating innovative culture, etc.

\section{Mechanics:}

Mechanics are the basic processes that drive actin forward and generate players engagement (Werbach and Dan, 2012).

\section{Components:}

Components are the more-specific forms that mechanics or dynamics can take (Werbach and Dan, 2012).

The most important game dynamics, mechanics, and components have been summarized in Table 2.

Table 2. Game dynamics, mechanics, components by Werbach and Dan (2012)

\begin{tabular}{|c|c|}
\hline \multirow{5}{*}{ 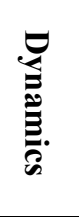 } & Constraints \\
\hline & Emotions \\
\hline & Narrative \\
\hline & Progression \\
\hline & Relationships \\
\hline \multirow{10}{*}{ 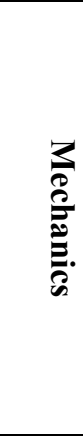 } & Challenges \\
\hline & Chance \\
\hline & Competition \\
\hline & Cooperation \\
\hline & Feedback \\
\hline & Resource \\
\hline & Rewards \\
\hline & Transactions \\
\hline & Turns \\
\hline & Win States \\
\hline \multirow{15}{*}{ 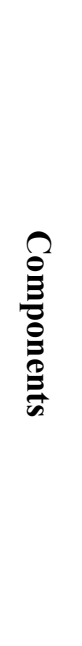 } & Achievements \\
\hline & Avatars \\
\hline & Badges \\
\hline & Boss Fights \\
\hline & Collections \\
\hline & Combat \\
\hline & Content Unlocking \\
\hline & Gifting \\
\hline & Leaderboards \\
\hline & Levels \\
\hline & Points \\
\hline & Quests \\
\hline & Social Graphs \\
\hline & Teams \\
\hline & Virtual Goods \\
\hline
\end{tabular}

According to Li (2014) another well-cited framework is the Yu-kai Chou's Octalysis Gamification framework (see Figure 2), where he provided a comprehensive collection of game elements. 


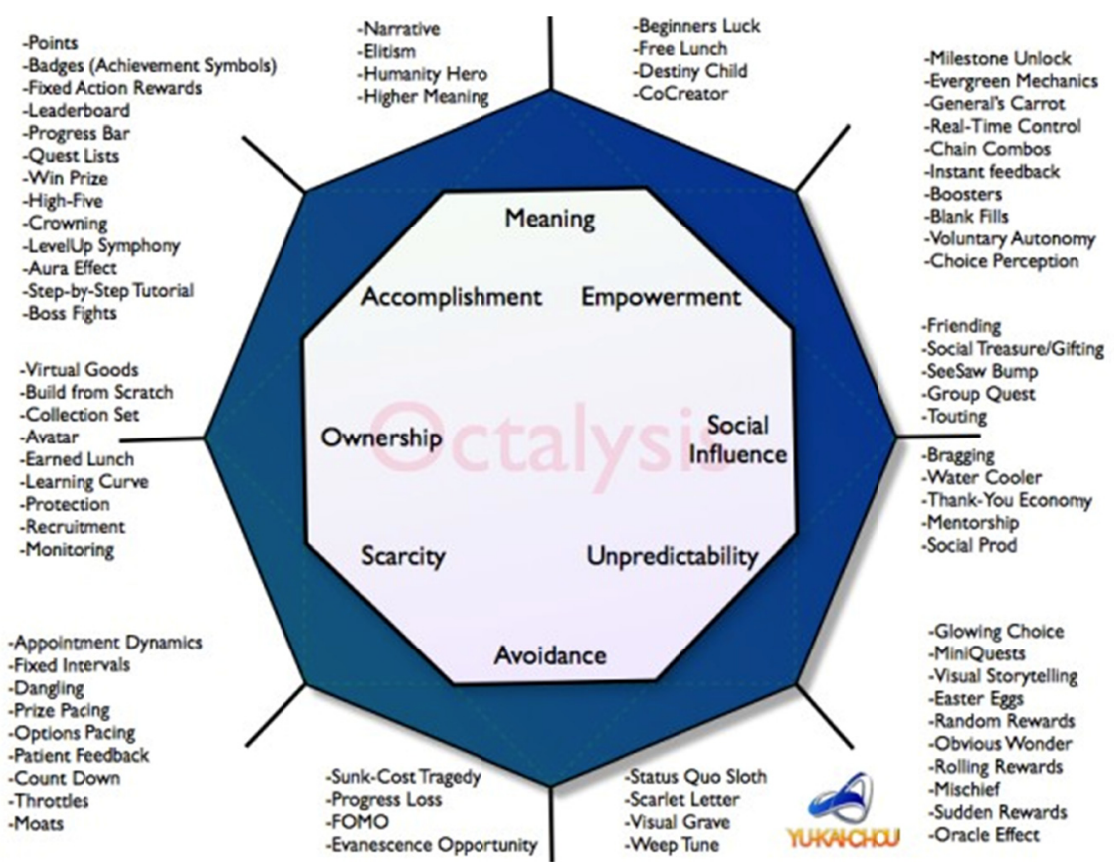

Figure 2. Yu-kai Chou's Octalysis Gamification framework

\subsubsection{History and Timeline of Gamification}

Even though the concept only appeared recently in 2010 (Rughiniş, 2013) (see Figure 1 (Morford, Witts, Killingsworth, et al, 2014)), the concept of Gamification has been around for much longer time (Morford, Witts, Killingsworth, et al, 2014).

According to Li (2014), "In the early 1980s, Malone issued the question 'How can the features that make computer games captivating be used to make other user interfaces interesting and enjoyable to use?' in his paper", where Malone suggested the use of game features in designing systems to make them more enjoyable (Li, 2014). In the 1990s and 2000s, the field of user experience became more popular in order to enhance user satisfaction (Rampoldi-Hnilo \& Snyder, 2013). According to Li (2014), the first appear to the Gamification was in 2002 by British-born computer programmer and inventor Nick Pelling. Unfortunately, the concept didn't get attention until 2010 (Li, 2014). Even in the academic field, Gamification started getting attention concept became more popular and cached the attention in the academic field since 2010 as Figure 3 indicates.

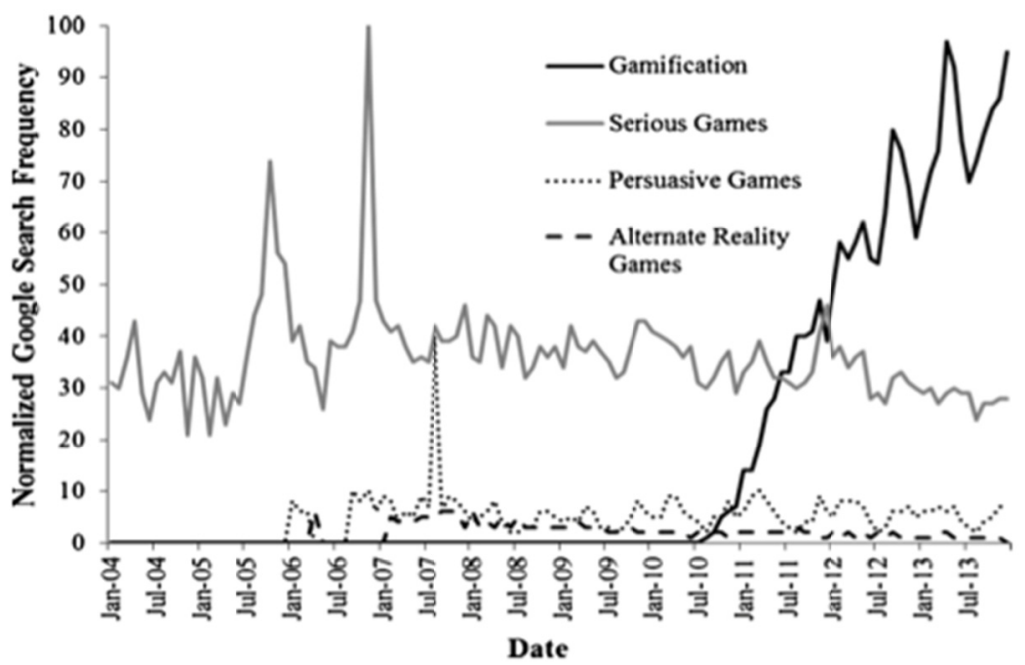

Figure 3. A comparison of Google search frequencies (worldwide) of four different terms related to the notion of

"Gamification" from January 2004 through December 2013 (partial data). The data depict comparisons of the normalized frequency of searches for each term (Morford, Witts, Killingsworth, et al, 2014). 


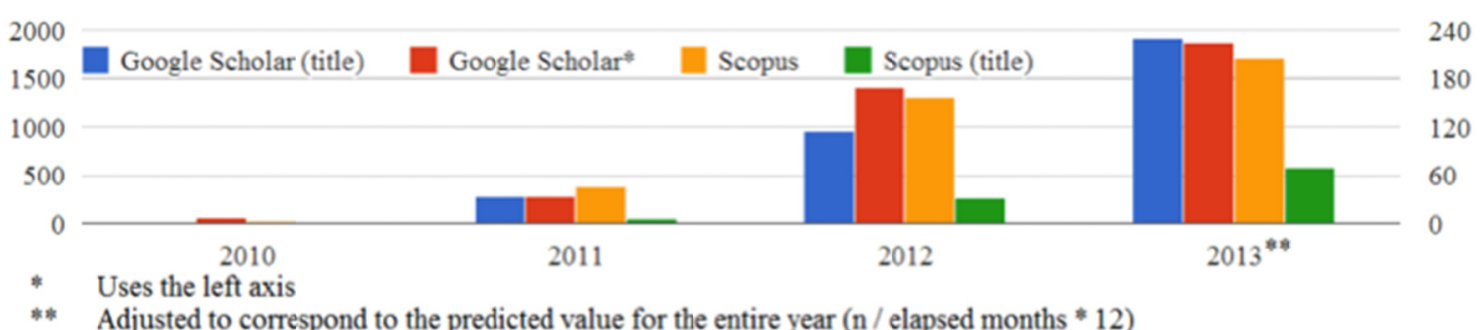

Figure 4. Gamification in academic search engines (Hamari, Koivisto, et al, 2014)

By 2011, the Gamification is still considered to be a popular emerging concept (Fu, 2011), where Fu (2011) stated, "a report by information technology research company Gartner, Inc. predicted that by 2015 , more than $50 \%$ of organizations will gamify their innovation processes. The report also concludes that by 2014 , more than $70 \%$ of Global 2000 organizations will have at least one gamified application".

Markets and Markets (Nov, 2014) in their "Worldwide Market Forecasts and Analysis (2013 - 2018)" paper have estimated that Gamification growth will go from $\$ 421.3$ million in 2013 to $\$ 5.502$ billion in 2018 .

\subsubsection{Platforms}

While the market acknowledge the fast growth of the Gamification field, a number of vendors have already developed their own Gamification Platforms, ready to be customized to specific organization needs (Maan, 2013). These Platforms are summarized in the following table (Table 3):

Table 3. Gamification platforms referenced by different papers

\section{Gamification Platform(s)}

BadgeVille (commercial), Bunchball (commercial), Actionable (commercial),

Gamify, BigDoor (commercial), CrowdFactory, Sociallype, Gigya (commercial), Badgy, Gamification, Fusion, Hoopla, CrowdTwist, Bulbstorm,

Nicely, MindTickle.

Mozilla OpenBadges (open source), Userinfuser (open source), Badgeville (Herzig, Ameling, et al, 2012) (commercial), BigDoor Media (commercial), Bunchball (commercial).

BadgeVille (commercial), Bunchball (commercial), BigDoor Media (Xu, 2011) (commercial), Mozilla OpenBadges (open source), UserInfuser (open source).

\subsection{Enterprise Gamification}

Businesses in different sizes are eager to succeed in their fields, even though the globalization didn't make that easy for them to accomplish that due to increment of competition between them. Moreover, the competition made them more customer-focused and trying their best to gain their satisfaction. In order to make that possible, enterprise's software came to the rescue. According to Kumar (2013) "enterprise software refers to software that businesses use to run their day-to-day activities such as finance, sales, human resources, manufacturing, shipping, and procurement". Moreover, Gamification has become an emerging concept to ensure user engagement through these software and the business processes in general in effective and efficient manners. Kumar (2013) has emphasized that Gamification has arisen in business due to "the changing nature of information work, entry into the workforce of digital natives, a new generation that has grown up playing online and video games, and the wide spread adoption of social media and mobile technology".

\subsubsection{Benefits}

Businesses use Gamification to enhance user engagement both employees and customers in order to improve their services quality and achieve their goals faster. Various papers have agreed on the positive impact of Gamification on the intrinsic and extrinsic motivation of users (Blohm \& Leimeister, 2013; Llagostera, 2012; Maan, 2013). According to Oprescu, Jones, et al (2014), businesses can gain benefits from Gamification, including: promoting loyalty, productivity, and wellbeing in the workplace.

Rough (2013) have identified these benefits as follows: 
- Spurring innovation.

- Motivating and retaining employees.

- Engaging internal and external communities.

- Increasing engagement, adoption, learning, and loyalty.

- Increasing revenue from software trials.

- Raising efficiency and quality of service.

- Helping the enterprise stay competitive within the industry.

- Meeting customer expectations.

- Reducing time and costs.

- Increasing return on investment (ROI).

- Driving profits.

2.2.2 Challenges, Limitations, and Threats

Gamification as an evolving concept is facing various challenges and threats that can eliminate its implementation or make it difficult to be adopted. They include:

- Gamification is for short-term goals not for the long-term ones: according to he found that engagement and the role of Gamification in motivation and in achieving the desired goals fades with time (Nicholson, 2012).

- Ethical issues related to Gamification: which include the user privacy and his data (Schacht \& Schacht, 2012). Moreover, it is important to remember that Gamification is should be to motivate users not to manipulate them.

- Corporate culture: unfortunately, some of the businesses view Gamification as wasting of time (Schacht \& Schacht, 2012).

\subsection{Gamification in Saudi Arabia}

Even though, that the Saudi market have recognized the Gamification role and success in engagement and motivation by the emergent of new specialized entrepreneurial businesses in providing Gamification solutions, but still there is an evident lack of employing Gamification concept in different business fields.

There a plenty of specialized Gamification solutions providers in GCC, including:

- The Gamifiers, which recently has exclusively partnered with Badgeville to provide Gamified solutions for both customers and employees engagement to the Middle East, mainly: Saudi Arabia, United Arab Emirates, Egypt, and Kuwait. The Gamifiers is located in Dubai, United Arab Emirates.

- The Gamified Labs, another Dubai-based Gamification solutions provider that produced different gamified applications in different areas, including: education and sport.

Unfortunately, no obvious utilization of Gamification has been noticed in the business nor other fields expect few that will be mentioned later.

In the academic point of view, a notable lack of research on this area have been detected, only three published papers have been found about Gamification, including:

- "Gamification In Arabic Interactive Educational Applications: Cultural And Language Considerations In Motivational Affordances Of Design Elements", where the authors (Alkwai, Alkheibary, and Almoaythir, 2014) have focused on examining the usability and the interface design of gamified educational Arabic applications.

- "Gamification to Improve Adherence to Diabetic Treatment in Saudi Arabia", where the authors (Alaa, Gary, and Ashok, 2014) have presented "Sukr" an online system that help Saudi diabetic patients to manage their diabetes. The results were magnificent where it resulted the success of achieving the objectives and recommended using this gamified online tool to help the diabetic patients.

- "Making Arabic PDF books accessible using Gamification", where the authors (AlRougi, AlKhalifa, 2014) have developed a gamified system to enhance Arabic PDF books accessibility. 
In conclusion, the Gamification has been noticed academically in the fields of: education, usability, and healthcare.

\subsubsection{Enterprise Gamification in Saudi Arabia}

As mentioned before, Saudi Arabia still lacking Gamification employment or, at least, utilizing some of its aspects without realizing that it is Gamification. Several of available applications in the market approve that enterprise Gamification employed and effectively achieves its goal in different business functions. For example:

\subsubsection{Loyalty programs in Telecommunications Industry}

STC and Mobily, the leaders in the telecommunication industry, have points system to gain their customer loyalty and to increase engagement with their customers, and the customers with each other.

STC's Qitaf system lets users replace each 10 SR they spent with 1 point, where they collect and replace it with different prizes, which are STC services, including: free Minutes and free SMSs. Also, users can exchange these points with physical rewards from different physical stores. Moreover, users can gift it to their friends or other STC users.

With the same concept, Mobily provides its customer with the ability to replace every 1SR spent with points and then exchange it to various prizes in their loyalty program, named "Niqaty".

\subsubsection{Loyalty Program in Saudi Airlines (Alfursan)}

Alfursan program replaces the miles that the customers cross with points that will be replaced with prizes, that include flight tickets, luggage allowance, personalized luggage tags, and other physical rewards.

\subsubsection{Loyalty program in Sephora}

Sephora is one of the huge cosmetic retailers in Saudi Arabia and the GCC. Sephora's unique loyalty program targets Saudi Arabia, Qatar, Bahrain, and United Arab Emirate. Sephora's special loyalty program utilizes more than points of game elements, as clarified in the following table:

Table 4. Game elements in Sephora's gemified loyalty program

\begin{tabular}{|c|c|c|}
\hline Game Element Type & Game Element & Description \\
\hline Dynamics & Constraints & $\begin{array}{l}\text { - You should spent at least 10SR to gain points (see } \\
\text { Figure 5). }\end{array}$ \\
\hline Dynamics & Emotions & - You will receive a gift in your birthday (Figure 6) \\
\hline Dynamics & Progression & $\begin{array}{l}\text { There are levels represented with different colored } \\
\text { cards. } \\
\text { Moreover, progression is represented with earned } \\
\text { points bars that need to be filled to level up and } \\
\text { progress (see Figure } 5 \text { \& Figure } 7 \text { ). }\end{array}$ \\
\hline Mechanics & Competition & $\begin{array}{l}\text {-Competition between employees to reach the top } \\
\text { of the mountain. Top ten list provided weekly. }\end{array}$ \\
\hline Mechanics & Win-state & - After completing each level a pop up will appear \\
\hline Mechanics & Feedback & $\begin{array}{l}\text { - Feedback is provided through the progress bars } \\
\text { (Figure 7) and points after each purchase process. }\end{array}$ \\
\hline Mechanics & Rewards & $\begin{array}{l}\text { Rewards are earned in shape of: points, physical } \\
\text { gifts, cards, after specific times of purchases. } \\
\text { (Figure 6) }\end{array}$ \\
\hline Components & $\begin{array}{l}\text { Achievements, } \\
\text { Badges, Levels }\end{array}$ & $\begin{array}{l}\text { Represented with three cards: white (beginner), } \\
\text { Black (after earning } 200 \text { points), Gold (after } 1500 \\
\text { points). See Figure } 5 \text {. }\end{array}$ \\
\hline Components & Content Unlocking & Progress bar (see Figure 7) \\
\hline Components & Gifting & $\begin{array}{l}\text { Physical gifts, private sales, special offers, } \\
\text { invitations to events (Figure 6). }\end{array}$ \\
\hline Components & Points & 1 point $=10$ SR $($ Figure 5$)$ \\
\hline
\end{tabular}




\section{DISCOVER BEAUTY without frontlers}

With the Sephora Card Program, your beauty purchases add up to points which you exchange for gorgeous free gifts.
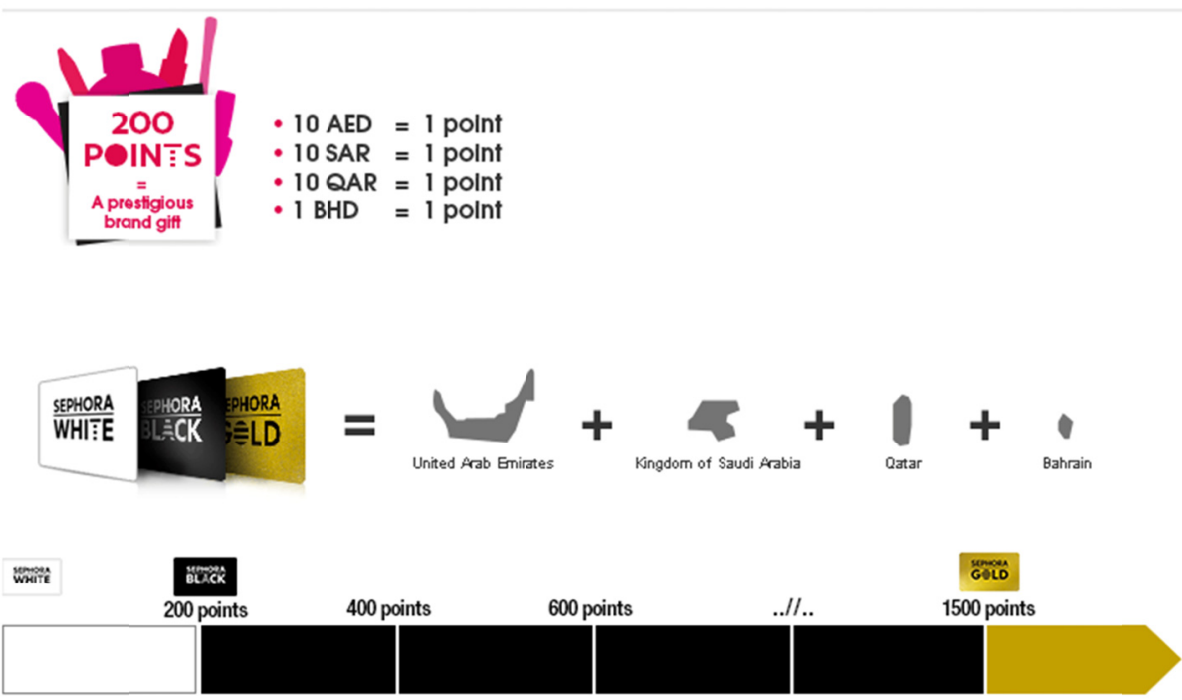

For each two hundred (200) points accumulated the cardholder will receive by email a giff voucher to redeem against one (1) gift to be chosen by the Loyal Customer from a selection made by Sephora in its absolute discretion.

Figure 5. Some of the game elements for the Sephora loyalty card, including (points, progress bar, rewards, levels, progression)

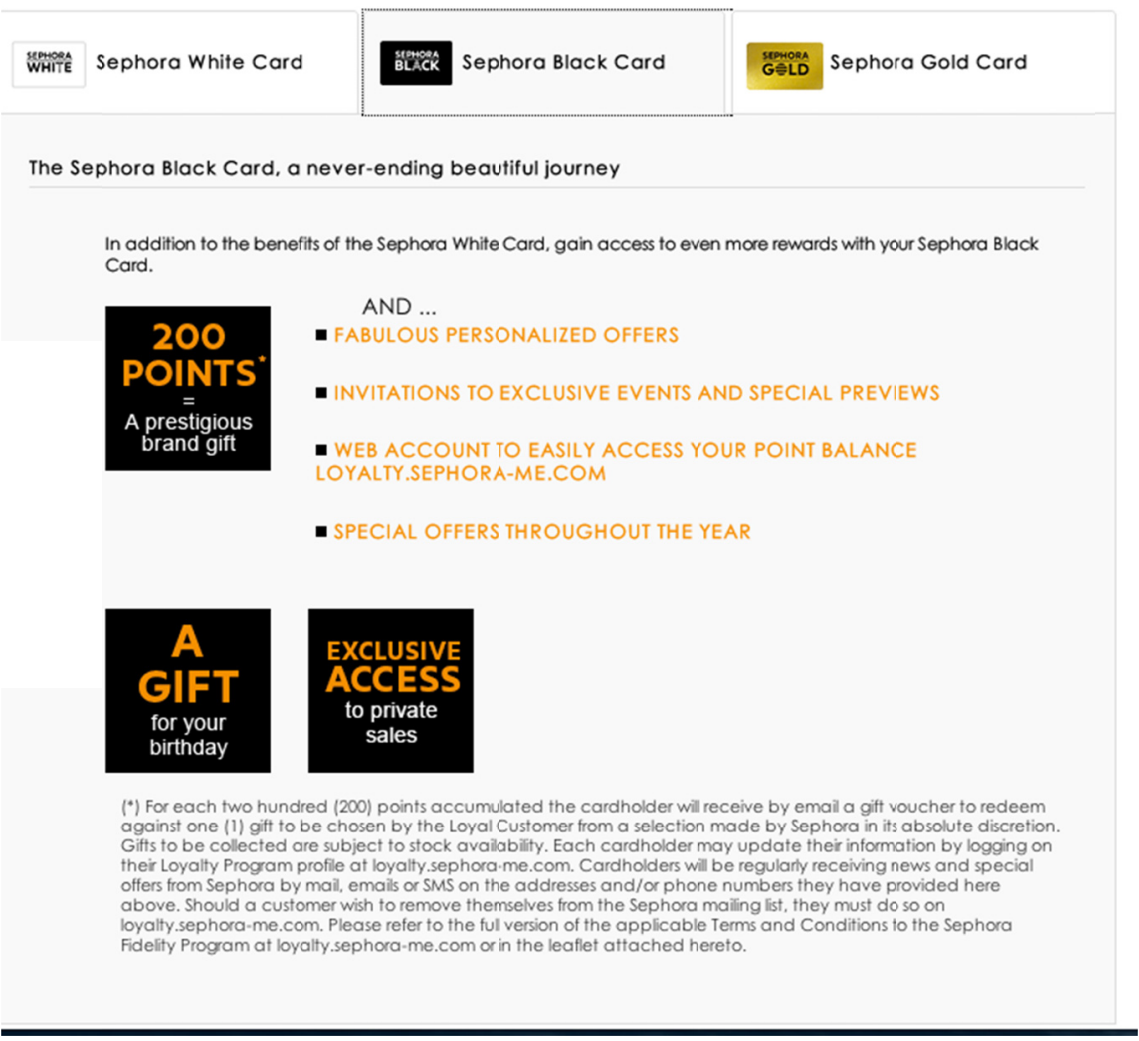

Figure 6. Presenting the rewards and gifting for each level (card) 


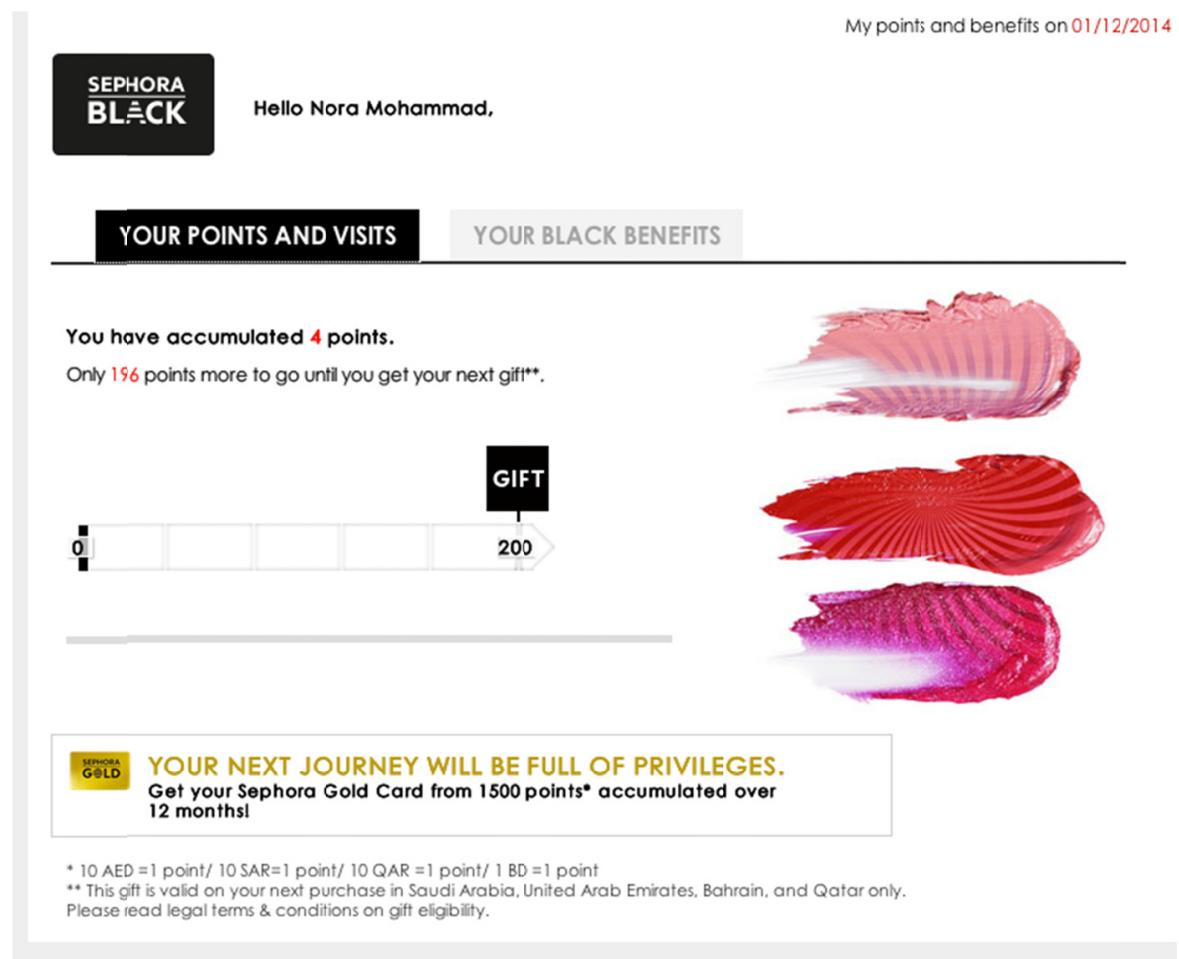

Figure 7. Presenting progress, feedback, and content unlocking

\subsubsection{Nitaqat from Ministry of Labor (First Gamified Governmental System)}

Nitaqat, The Saudization program, was developed in the aim to motivate private businesses to provide Saudi employment in their businesses. Nitaqat has been launched by the Ministry of Labor in 2011.

Nitaqat is an interesting online system that categorizes private sectors into different colors based in the Saudi employees percentage (see Figure 8). Nitaqat is designed to be honest, practical, motivational, fair, and realistic.

Before producing this coloring classification, Ministry of Labor has to update and recategorize the business categories in Saudi Arabia from 11 to be more than 41 accurate business categories to be make it easier to create the system and to make it even clearer to the businesses. Moreover, Ministry of Labor have redefined business sizes based on employees' numbers to be:

- $\quad>10$ employees, very small.

- $\quad 10-49$ employees, small.

- $\quad 50-499$ employees, medium.

- $\quad 500-3000$ employees, large.

- $\quad<3000$ employees, very large.

Nitaqat presented four colors, Platinum (blue in the previous figure), green, red, and yellow. Each color means a certain percentage of Saudization depending on their business size. Moreover, each color has its own customized and updated rewards (Figure 8), for example:

Small retailer business that have from 10 - 49 workers, where they are 16,000 businesses in Saudi Arabia; the coloring classification goes as follows:

- $\quad$ Platinum: $>10-27 \%$ of workers are Saudis (High Saudization).

- $\quad$ Green: $10 \%$ of workers are Saudis.

- $\quad$ Yellow: between 4-10\% of workers are Saudis.

- $\quad$ Red: $4 \%$ of workers are Saudis (Low Saudization). 
Table 5. Nitaqat classification

\begin{tabular}{|c|c|c|c|}
\hline $\begin{array}{l}\text { BLUE } \\
\text { VIP }\end{array}$ & $\begin{array}{l}\text { GREEN } \\
\text { Excellent }\end{array}$ & $\begin{array}{c}\text { YELLOW } \\
\text { Poor compliance }\end{array}$ & $\begin{array}{c}\text { RED } \\
\text { Non-compliance }\end{array}$ \\
\hline $\begin{array}{l}\text { INCENTIVES: } \\
\text { Can hire employees } \\
\text { from any country } \\
\text { Easier visa processing } \\
\text { Condition-free visa } \\
\text { transfer: } \\
\text { Can hire employees } \\
\text { from Red zone and } \\
\text { Yellow zones, and } \\
\text { transfer their visas } \\
\text { without the permission } \\
\text { of their current } \\
\text { employers }\end{array}$ & $\begin{array}{l}\quad \text { INCENTIVES: } \\
\text { Can apply for new visas } \\
\text { once every two months } \\
\text { Can change their foreign } \\
\text { workers' profession } \\
\text { except to those } \\
\text { restricted to Saudis }\end{array}$ & $\begin{array}{l}\quad \text { PUNITIVE } \\
\quad \text { MEASURES: } \\
\text { Cannot apply for new } \\
\text { visas } \\
\text { Can get only one visa } \\
\text { after the departure of } \\
\text { two expatriates } \\
\text { Cannot transfer visas } \\
\text { and change professions } \\
\text { Grace Period: } \\
\begin{array}{l}\text { Nine months to improve } \\
\text { their status }\end{array}\end{array}$ & \begin{tabular}{l}
\multicolumn{1}{c}{ PUNITIVE } \\
MEASURES: \\
Banned from change of \\
profession, transfer of \\
visas, issuance of new \\
visas and opening files \\
for new branches
\end{tabular} \\
\hline
\end{tabular}

According to the chairman of Jeddah commerce Chamber (2014), Nitaqat has successfully employed more 400,000 Saudi, 1400 from them were jobless.

Saudi Arabia and Middle East in general are promising market for Gamification and user engagement in general. Therefore, it is important to have a standard framework that can be used to measure Gamification efficiency.

\subsection{Employee Engagement}

According to Naseem et al (2011) "The need to enhance employee satisfaction is critical because it is a key to business success of any organization." Webb and Cantu (2013) have explained "The idea is that if employees are engaged in their work, they will be more involved in things that make the company successful." Moreover, Webb and Cantu (2013) have clarified Employees' engagement, as "the degree or extent to which employees feel committed to their work and their organization". Engaged employees can lead their employers to success in many ways as follows (Baumruk and Gorman, 2006; Sridevi, 2010):

- Say -the employee advocates for the organization to co-workers, and refers potential employees and customers

- Stay -the employee has an intense desire to be a member of the organization despite opportunities to work elsewhere

- Strive-the employee exerts extra time, effort and initiative to contribute to the success of the business

In conclusion, enterprise Gamification has an evident and important role on enhancing performance of both employees and customers. The previous studies have helped in realizing and selecting the instruments that will be used in data collection to include a survey and monitoring approaches.

\section{Methodology}

This research is a case study that uses a mixed methodology, a qualitative methodology by using monitoring approach and a quantitative one by using a survey approach.

This research focuses on the analysis of the resulted surveys and interviews data and the monitored employees' performance while using "The Lord of ABANA", the gamified system, as a case study in ABANA Enterprises Group Co.

\subsection{Research Sample}

In this exploratory study research, a purposive sampling has been used to meet the research objectives. 20 employees from different departments that use "The Lord of ABANA" at ABANA Enterprises Group Company are selected to participate. The selection of the sample depended on being the only employees who use the gamified system and their willingness to participate.

\subsection{Research Population}

While, Gamification implementation is considered to be rare and still unusual in Saudi Arabia especially in the 
business and enterprise field, ABANA Enterprises Group Co. is pioneering in implementing Gamification due to ABANA's realization and understanding of its employees' role in rising ABANA's institution into the highest levels in its field. Therefore, ABANA implements different employee engagement concepts, including Gamification to improve their performance and to make the environment more enjoyable and fun to work in.

\subsubsection{Why ABANA?}

ABANA Enterprises Group Co. has always been supportive and eager to encourage its employees to complete their studies by creating a convenient environment and providing their employees with any kind of help they can offer, which is a great privilege to the researcher as an employee in this marvelous institute. Therefore, this ABANA"s support have been one of the first reasons of choosing ABANA as a case study.

Moreover, ABANA's adoption of the concept of helping its employees in their studies have impacted its employees to support their colleagues, which is another privilege that the researcher have gained.

One of the most important reasons is that ABANA Enterprises Group Co. is considered to be a representative organization of their fields. Moreover, it is well known for their great technologies that innovate the market and make them one of the leaders in the market.

\subsubsection{ABANA Enterprises Group Co.}

ABANA is a Saudi-based privately held company that aims to provide hardware and software solutions for banking and telecommunication sectors in Saudi Arabia.

In 1977, Mr. Abdulrahman Bin Jebreen, the Chairman of ABANA, and Mr. Abdullah Bin Jebreen, the Chief Executive Officer, co-founded ABANA as a trading and contracting establishment. Now, ABANA is considered to be a large-sized company that has 21 branches around Saudi Arabia with more than 800 employees. ABANA run as a third party that cooperates with its global partners to provide their customers with various products and services. Moreover, ABANA provide in-house services to their customers. ABANA promises its customers to provide them with support in less than 24 hours. ABANA's mission is "providing excellent quality products and services that satisfy our customers".

ABANA has a flat organizational structure (Figure 8), where it is considered to be a partnership company that has three main business units (departments):

- Banking: managed by Mr. Amr Al.Amr, the general manager of the banking unit, where ABANA provides its customers with different banking products and solutions, including: ATMs services, products and solutions, currency counting machines, teller assistant units, customer flow management services, exchange rate boards, and ATM management and monitoring services. 350 employees work in the banking unit with the aim to provide their customers, not only with high-qualified products, but also with outstanding customers support. Therefore, banking unit has several departments to achieve that goal, including: executive management, Technical Services Department (TSD): (it manages the following teams: Field Service - PVT sector, Saudi Post POS Project Technical Services, Installation Team, Workshop, Advanced Group (product Specialist), Site Audit Project Team, Branch Audit Project Team, and Help desk Department), and Marketing \& Sales Department (manages the following teams: Marketing \& Product Management, Sales and Relationship Management, Retail Sales, Project Management, Technical Sales Support, and Sanid project team).

- Cash Management Services (CMS): managed by Mr.Fawad Karman, the general manager of the cash management services unit, to provide the banking sectors and cash units in Saudi Arabia with cash management services and solutions in a secure environment. CMS is a new unit that has split from the banking unit recently at the end of 2014 to concentrate its efforts in providing customers with more focused services. The unit is still new, therefore it has a few number of employees. 24 employees work in the Cash Management Services unit in the following departments: CMS management, CMS Operations, and CMS Field service.

- Telecom: leaded by Mr. Al-Abdulkarim, the general manager of the telecom unit, with the aim of providing the telecommunication's carriers in Saudi Arabia with various products and services, including: wireless and wired products and services, fiber optic solutions, operation and maintenance solutions, installation and integration services, and network mobile solutions. To achieve their goals, telecom unit has more than 300 employees distributed in several departments including: Telecom management, Telecom Wimax project, Telecom fixed line project, Telecom MOE project, fixed line manpower, Telecom FTTH project, Telecom FTTX project, Telecom NGN Project, Telecom NGN Outsource, OSP project, Telecom SLA project, Telecom Technical support, and FTTX Outsource team. 
- $\quad$ ABANA has a supportive unit to achieve common and overall objectives that are needed to harmonize the work between the units, called "Corporate". Corporate is managed by Mr. Bernd Clemens, the general manager of the corporate unit, and has several departments, including: Executive Management, Administration Department (manages the following departments: branding, general administration, housekeeping team, quality assurance, back office and purchasing, warehouse, infrastructure management), Human resources department, Government relations, and Finance department.

Banking unit, telecom unit, cash management services unit, and corporate unit report to ABANA's CEO Mr. Abdullah Bin Jebreen.

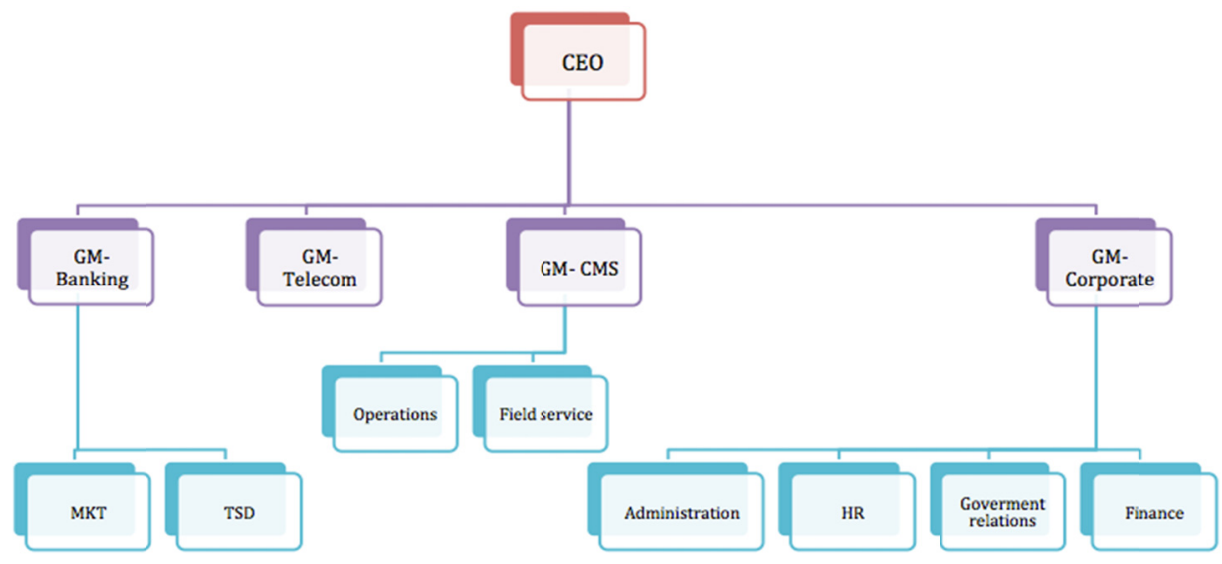

Figure 8. ABANA's Organizational structure

\subsubsection{Employee Engagement at ABANA}

Starting from its vision (Figure 9), ABANA is clearly eager to establish a good long lasting relationship with their employees by engaging with them in different ways, including:

- Regular events and gatherings: ABANA holds events regularly where employees have an enjoyable time engaging with each other.

- ABANA's training and development center: ABANA has established recently training center to encourage employees to develop their skills and expertise in any possible for them to reach either online or offline.

- The Employees of the Quarter Reward: ABANA recently launched the employee of the quarter award in ABANA in the 2014's $3^{\text {rd }}$ quarter. The reward will be given through a certain process.

- The Annual chairman Award event: an event that is held annually to reward the employees based on their seniority appreciating their loyalty to ABANA.

\section{TO OUR CUSTOMERS \\ ABANA will work closely with its customers to improve the efficiency and profitability of their operations with the latest in technology and the finest in service.}

\section{TO OUR PARTNERS}

By putting the customer's best interests and satisfaction ahead of everything else, ABANA will carefully select products and services from those vendors who share ABANA's standards for high quality and superior customer service.

\section{THE ABANA TEAM}

ABANA's success depends on the creativity, hard work and dedication of its employees. In return, ABANA provides its employees with the opportunity for advancement, job security, recognition of a job well done, and the satisfaction of working together for the well-being of their families, the Company, and the Country.

Figure 9. ABANA's vision (ABANA Enterprises Group Co., 2014) 
Moreover, ABANA has successfully created a very friendly work environment as been agreed on by most of its employees. However, some of the daily tasks in some of ABANA's departments are seen as routinely tasks that lack competitiveness and need lot of motivation. Therefore, "the lord of ABANA", a gamified web-based application has been launched targeting these kind of issues and trying to enhance employees performance on these tasks. Moreover, this kind of application aims to engage more with the employees and to provide them with fast feedback.

\subsubsection{The Lord of ABANA- The Gamified System}

Even though, the human resources, finance, and banking sales teams in ABANA are working hard and doing their duties in an acceptable manners, the routinely tasks and frequent work that employees face every day, besides the lack of competition that the employees deal with have decreased the engagement some how.

Recently, ABANA launched its gamified online system, The Lord of ABANA, with the aim of enhancing human resources, finance, and sales employees' behavior toward their work and routine tasks. The gamified system have been developed using HTML, JavaScript, CSS3, and PHP to produce an easy to use and user friendly web application that is installed in ABANA's intranet to insure that they only use it in work hours and to achieve the desired objectives.

The application has gotten its power thanks to the support of each department manager, their encouragement to include the application with ever day tasks and the top management support. Moreover, the application have been developed based on employees' interests and customized to attract them.

Unfortunately, "The Lord of ABANA" has gotten some pros and cons that will be discussed later in the findings.

\subsubsection{System Objectives}

"The Lord of ABANA" application is a short-term online application that has been developed with month duration to fill the gaps and to achieve the following objectives:

- Increasing competition between employees even if they have different tasks in a social friendly environment.

- Improve employees' attendance and exit times.

- $\quad$ Improve employee engagement and motivate them.

- $\quad$ Provide them and their managers with fast feedback about their performance in weekly basis.

\subsubsection{System Design (Used Game Elements)}

"The Lord of ABANA" application (Figure 10) is developed based on the employees' interests, which were found through interviews that have been done with them before starting creating this application.

The application is inspired by the movie "the lord of the rings" where most of the employees have agreed on watching movies as one of their main enjoyable and fun things to do in their day. "The Lord of ABANA" story is that each employee is considered to be a warrior that has to earn points in order to level up so he can reach the top of the mountain and become the lord of ABANA and win the prize. "The Lord of ABANA" is easy to use and users only need to perform two actions, choosing from their tasks list and clicking the "submit" button (Figure 10). 

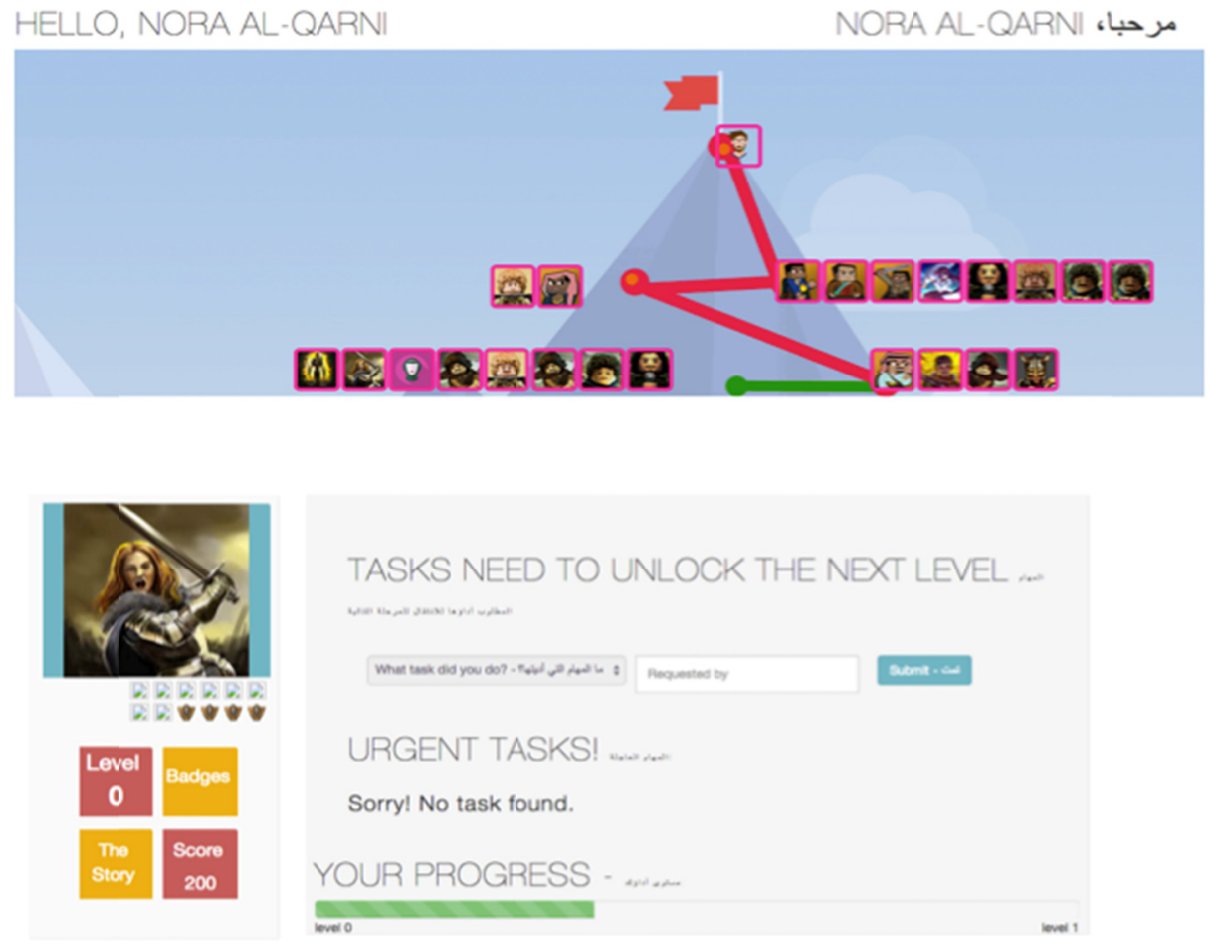

Figure 10. The Lord of ABANA Interface

"The Lord of ABANA" application is fully gamified system that has different game elements (Table 5), including:

Table 6. Lord of ABANA game elements

\begin{tabular}{|c|c|c|}
\hline Game Element Type & Game Element & Description \\
\hline Dynamics & Constraints & $\begin{array}{l}\text { Your attendance time should be before or at 8:00 } \\
\text { AM } \\
\text { Your exit time should be after or at 4:00 PM } \\
\text { You should submit your tasks after doing them } \\
\text { You should reach the top of the mountain first. } \\
\text { Managers' confirmation in doing the submitted } \\
\text { tasks. }\end{array}$ \\
\hline Dynamics & Emotions & $\begin{array}{l}\text { You will compete against your colleagues. } \\
\text { You will get a customized avatar. } \\
\text { You will be the lord of ABANA when you win. } \\
\text { You will get a prize when you win. }\end{array}$ \\
\hline Dynamics & Progression & $\begin{array}{l}\text { Progress bar that needs to be filled with points to } \\
\text { level up and progress. } \\
\text { The user position in the map represented by his } \\
\text { avatar. }\end{array}$ \\
\hline Mechanics & Feedback & $\begin{array}{l}\text { - Feedback is provided through the progress bar. } \\
\text { - The points after each submitted task. } \\
\text { - The user place in the map. } \\
\text { - The weekly report and analysis. }\end{array}$ \\
\hline Mechanics & Rewards & $\begin{array}{l}\text { Rewards are earned in shape of: points, physical } \\
\text { rewards, badges, and the lord of ABANA name. }\end{array}$ \\
\hline Components & Achievements, Levels & $\begin{array}{l}\text { Represented with the map and the progress bar and } \\
\text { winning against others. }\end{array}$ \\
\hline
\end{tabular}




\begin{tabular}{lll}
\hline Components & Badges & $\begin{array}{l}\text { Badges will be earned for, attendance, exit time, } \\
\text { competition, and submitting tasks. }\end{array}$ \\
\hline Components & Content Unlocking & Progress bar and map. \\
\hline Components & Social graphs & Represented by the map and statistics. \\
\hline Components & Avatars & Customized avatars based on each user. \\
\hline Components & Gifting & Physical gifts, badges. \\
\hline Components & Points & $\begin{array}{l}\text { Depends on each user tasks, frequency, and } \\
\text { importance of doing them. }\end{array}$ \\
\hline
\end{tabular}

\subsection{Research Design}

In this research, a short-term exploratory case study methodology is used to be able to achieve the objectives of this study. Moreover, the exploratory study methodology will help in exploring the factors and concepts. Furthermore, grounded theory strategy will be used to propose a framework, which has a relationship with the research and answering the research questions.

\subsubsection{Data Instrument}

As the research is designed to be an exploratory case study, the sources of the data are: the results of monitoring the gamified system, "The Lord of ABANA" and its database, where the monitoring includes: the submitted tasks, time, date, number, and assigned score for submitted tasks, and the employees' attendance and exit times. The results will be analyzed in certain criteria. Moreover, online surveys have been distributed via email to the employees using "The Lord of ABANA" to measure employees' personas, including: age, marital status, gaming experience, work environment and tasks related questions. Moreover, the survey will help in answering the research questions and objectives and to come up with the desired framework.

\subsubsection{Data Collection}

Data collection has been done through the two instruments mentioned earlier and discussed in the following:

\subsubsection{The Survey}

The distributed surveys (Appendix A) have provided first a short brief about the Gamification concept to help participants answer with clear understanding of what the study is. The questions that have been asked where divided into five parts:

- $\quad$ Personal information, including: age, department he is working under, and gender.

- $\quad$ Game experience, including: if he plays games or not and time spent playing games.

- $\quad$ Familiarity with Gamification concept, including: stating if they are familiar and have used the concept before or not.

- Motivation, including: explaining if they think this kind of concept can motivate users and why.

- Work environment, including: describing the work environment and how are they seeing it, if it is friendly, competitive, or cooperative.

The surveys are built, distributed, and analyzed through Google Docs.

\subsubsection{Monitoring and Observation}

The monitoring has been used in this study to explore the possible hidden patterns that might affect the study results. Moreover, the monitoring focused in the employees' performance in daily basis. Furthermore, the monitoring have been done during December 2014.

\subsubsection{Survey Validity and Reliability}

The surveys have been developed based on published and reliable previous studies, including: Meder, Plumbaum, \& Hopfgartner (2013) and Kumar (2013) studies. These studies have been chosen due to their suitability to this study.

\subsubsection{Data Analysis}

After gathering the data by monitoring the employees' performance while utilizing "The Lord of ABANA" application through the Internet, a data analysis application is used (SAP Lumira) to calculate, produce ad hoc reports and define the results. Moreover, the surveys were developed by Google Docs and distributed through each individual employee's email. Google Docs have been used to analyze the surveys' answers to deliver the results. 


\subsubsection{SAP Lumira}

SAP Lumira (formerly known as SAP Visual Intelligence) is one of SAP business intelligence solutions, which is visualization and data manipulation tool that connect to data sources, clean data, and visualize them with various graphical and user-friendly charts.

SAP Lumira comes in different and flexible platforms. SAP Lumira Desktop can be downloaded as software that works in different operating systems. SAP Lumira Cloud that is powered by SAP HANA, which is a hardware that works as in-memory processor, and provide the same functionality as the downloadable software. Also, the cloud version is mobile friendly and can be accessed by different browsers. Finally, an easy-to-use mobile application is provided. Users can easily access their SAP Lumira account from any platform or all of them simultaneously and he can find his data and view them, either locally or remotely.

SAP Lumira Desktop acquires data from different sources personal, direct connectivity, and via semantic layer. Moreover, it can make insight from different data types, either structured or unstructured. SAP Lumira Desktop let their users share their visualization by email or through Lumira Cloud.

SAP Lumira Cloud is easy to use by all of business people and different business sizes, where they can access it through their PCs (supported by different Oss), tablets, or mobile phones. SAP Lumira Cloud can access data and then explore it using interactive visualization in HTML5 to be able to view it either in mobile or desktop, and then share it to other users.

\subsubsection{Ethical Consideration}

All the data collected from the sample are considered to be confidential; employees have signed a disclosure statement and a consent form. Moreover, the participants are going to receive a copy from the results if they want to.

\subsubsection{List of Resources}

The sources needed, include:

- Online connection to be able to observe the performance of the sample.

- Authorization from ABANA's Human Resources, finance, and sales department managers to access employees' daily submitted tasks.

- Authorization from employees to access their information.

- Surveys distributed to the finance, Human Resources, and sales employees.

- Access to previous articles and researches.

- Laptop or desktop devices to measure user performance.

SAP Lumira cloud account to analyze the collected data.

\section{Results and Analysis}

SAP Lumira has helped in analyzing the data collected from SQL database, which have been generated by the employees submitted data regarding their completed tasks and daily performance, including: attendance and exit times.

Moreover, the data collected from employees answered surveys have helped in shaping the factors that should be measured when utilizing Gamification to enhance employees' performance.

\subsection{Survey Analysis}

Twenty employees use "The Lord of ABANA" application but only fifteen have participated in the study, which their surveys' answers resulted:

\subsubsection{Personal Information}

The participants are from three different departments, five of them from finance, five from human resources (from corporate unit) and five out of ten from sales from banking unit.

The employees' age ranges from twenty to forty, where seven employees' ages between twenty to thirty (generation $\mathrm{Y})$ and the rest eight employees' ages are from thirty-one to thirty-nine (generation X). Most of the employees are males (12 employees) and only three are females from the sales department.

\subsubsection{Game Experience}

55 percent of the employees have strongly agreed that they like playing video games, while 11 percent have chosen 
to be neutral and 22 percent have disagree. Their average playing times is two to three hours weekly.

\subsubsection{Familiarity with the Concept}

33 percent have strongly agreed on their familiarity with the Gamification concept, while 55 percent have agreed on the same thing, while 11 percent have disagreed.

\subsubsection{Gamification and Motivation}

33 percent have strongly agreed and 33 percent have agreed on its role in motivating people. 22 percent have chosen to be neutral, while 11 percent have disagreed.

\subsubsection{Work Environment}

44 percent have strongly agreed that the work environment is friendly, while 11 percent have agreed. On the other hand, 33 percent have chosen to be neutral, while 11 percent have disagreed. Although, 44 percent have strongly agreed that the work environment is routinely and boring, while 22 percent have agreed. 33 percent have chosen to be neutral, while the same percent have disagreed.

\subsection{Monitoring and Observation Analysis}

SAP Lumira provided and charts analyses of the daily performance of the employees in duration of one month, which is December of 2014. These analyses are based on: User id, department, date, tasks, and the number of tasks have been submitted, to provide the following results:

\subsubsection{Overall Users Daily Performance}

The following chart (Figure 11) presents the overall users daily-submitted tasks in December of 2014, where the weekend days have been excluded.

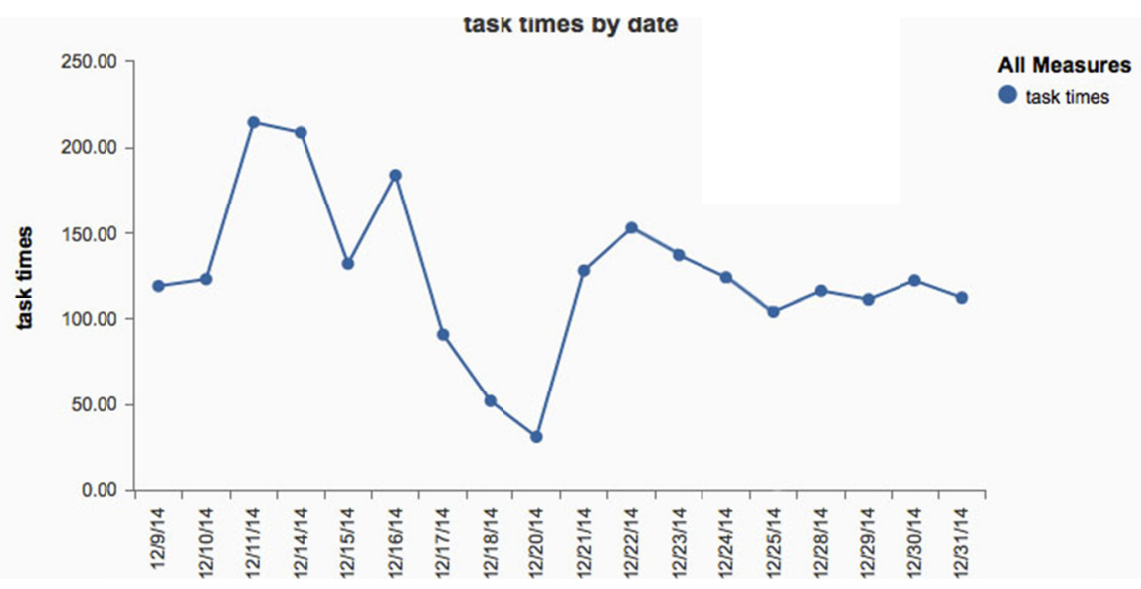

Figure 11. Employees daily performance. *"Times" indicates submitted tasks over the system

\subsubsection{Departments Performance}

The following chart (Figure 12) shows the overall performance of each department, including human resources, finance, and sales.
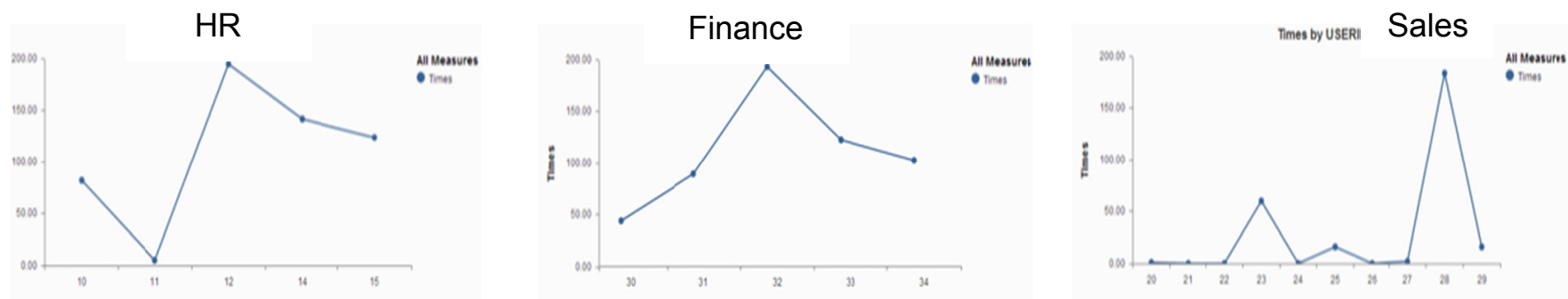

Figure 12. Departments overall performance 
Moreover, the following chart (Figure 13) presents the employees overall performance while they are classified based on their departments.

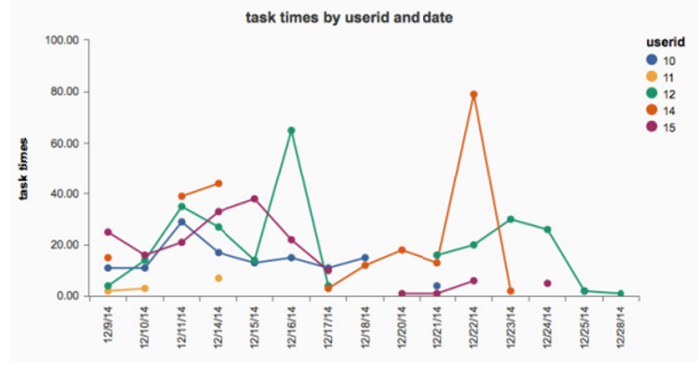

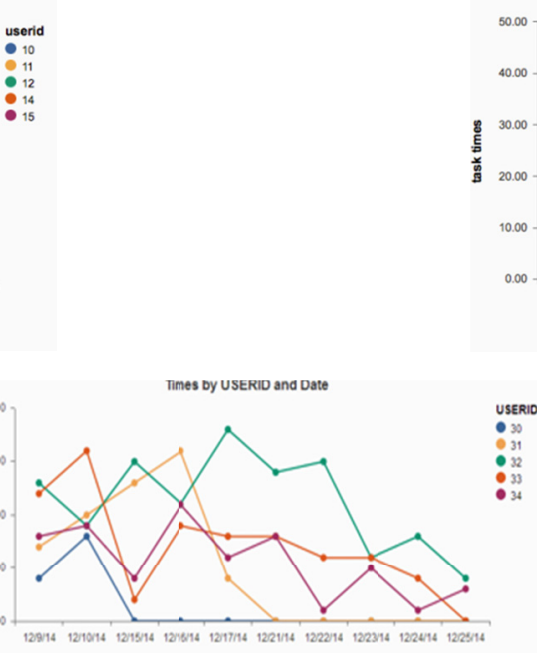

Date

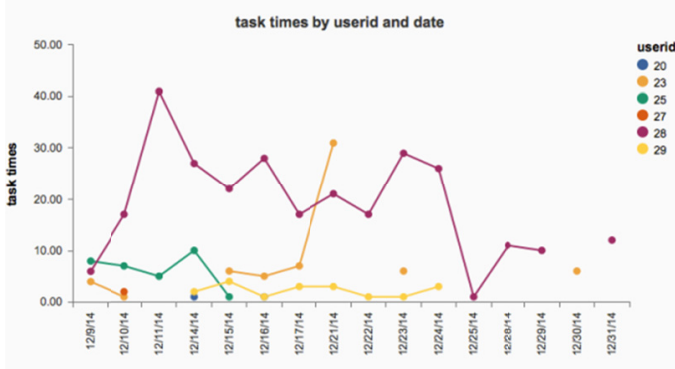

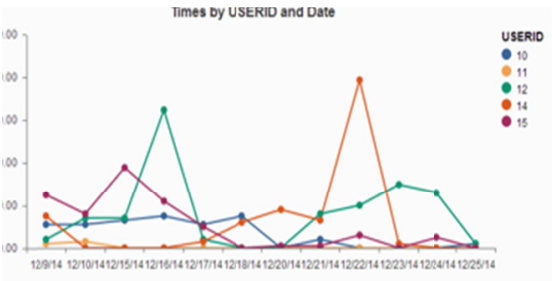

oate

FINANCE

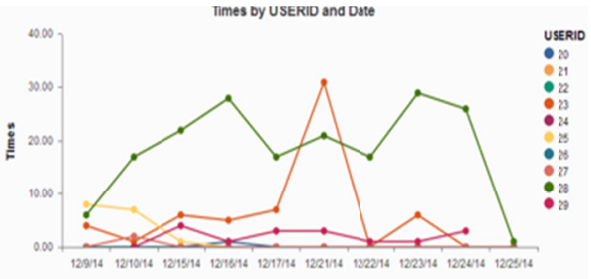

oate

HR

Figure 13. Each department individual employees daily performance

\subsubsection{Most Active Users}

The top three most active users in "The Lord of ABANA" are denoted in the following chart (Figure 14):

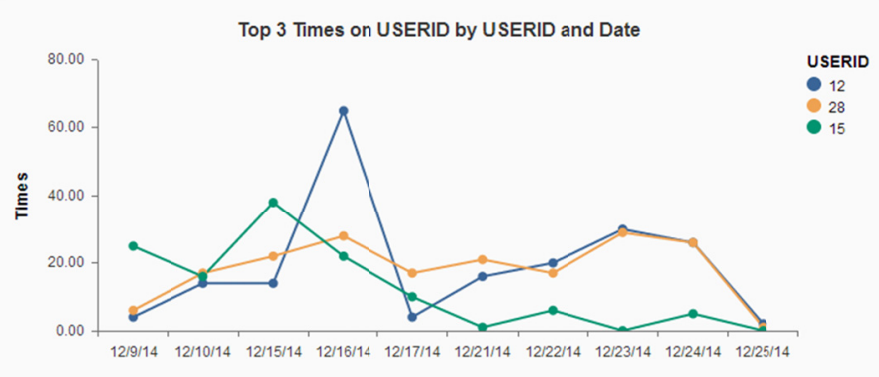

Date

Figure 14. Top 3 most active users (two of them from generation Y - 12 \& 28-, two of them play video games $-28 \&$ 15-, all of them are strongly agreeing in being familiar with Gamification concept, and all of them have strongly agreed on the positive impact of Gamification).

\section{Discussion}

After analyzing the data and presenting the results that can be categorized to factors that can be helpful for both practitioner and researchers in the Gamification field for enhancing employees' performance. Moreover, most of the resulted factors have agreed with previous studies.

The resulted factors are collected into four groups; three of them have a positive relationship with Gamification concept, while the remained one has a negative relationship with the Gamification concept. Following are these groups and their factors.

\subsection{Business Related Factors}

The resulted analyses from the employees' performance have shown the importance of management role in utilizing Gamification and achieving the goal of enhancing the employees' performance. The importance of management role 
has taken the shape of two important factors:

\subsubsection{Alignment with Business Strategy}

Gamification should not be considered as an addition technique that employee can perform; Gamification should be aligned with the business strategy.

Unfortunately in ABANA's case, "The Lord of ABANA" have been an addition and not aligned completely with the business strategy. Therefore, some of the employees didn't use it or their usage has decreased over time (see Figure 11).

\subsubsection{Top Management Engagement}

After noticing that the system needs more than just letting employees use it in their work day, their managers engagement have been added with the aim to help employees getting fast feedback from their managers. As the previous chart indicates (fig 11), top management engagement and usage of the system have encouraged and increased using the system from the employees, where their managers accept or decline each task they do giving them fast feedback and motivate them to do more.

\subsection{Technological Related Factors}

Another important group of factors have been resulted is the technological factors regarding two main factors, as follows:

\subsubsection{User Interface}

User interface should be user-friendly. Therefore, it should be easy to use, doesn't take time to interact with, and has the most important things only in a clear way.

In ABANA's case, some of the employees don't understand English, which have made it difficult for them to interact with the system. Therefore, Arabic has been added to the interface to make it bilingual, having both Arabic and English. Moreover, the employees have only to perform two clicks while using the system, which made it easy and increased their submission.

\subsubsection{Technology Experience}

The results (Figures 12 and 13) have shown that the employees who use complicated technology or enterprise software (ERP for example) are more active in using the gamified system than other departments that use less complicated technology (MS Excel for example) in their tasks.

The founded results in the technological factors prove what Kumar (2013) has emphasized and explained in his paper "Gamification at work: designing engaging business software".

\subsection{User Related Factors}

One of the most important factors' is the one that it is related to the user in general, and to the employees in this case. Employees are the customers that the content and the system should be focused on as the system was created for them. Therefore, to make the Gamification achieve its purpose, the following resulted factors should be considered:

\subsubsection{Employees Age}

As the following charts (Figures 15 and 16) indicate, the age of users is important. The younger the employee is the more active he become.

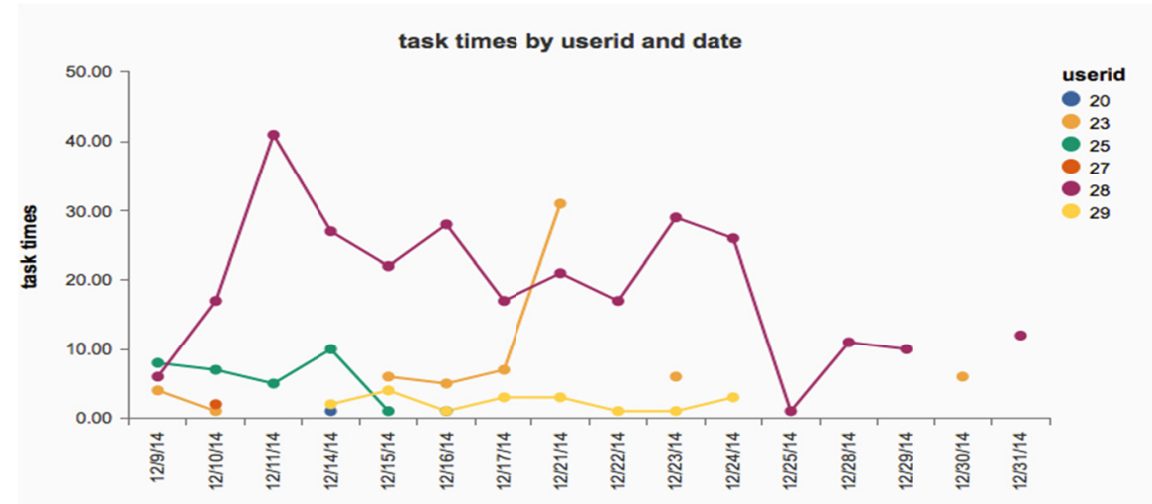

Figure 15. User 28 (the most active user from the sales department) was born in 1988. User 28 plays and loves video games. (Sales performance chart) 


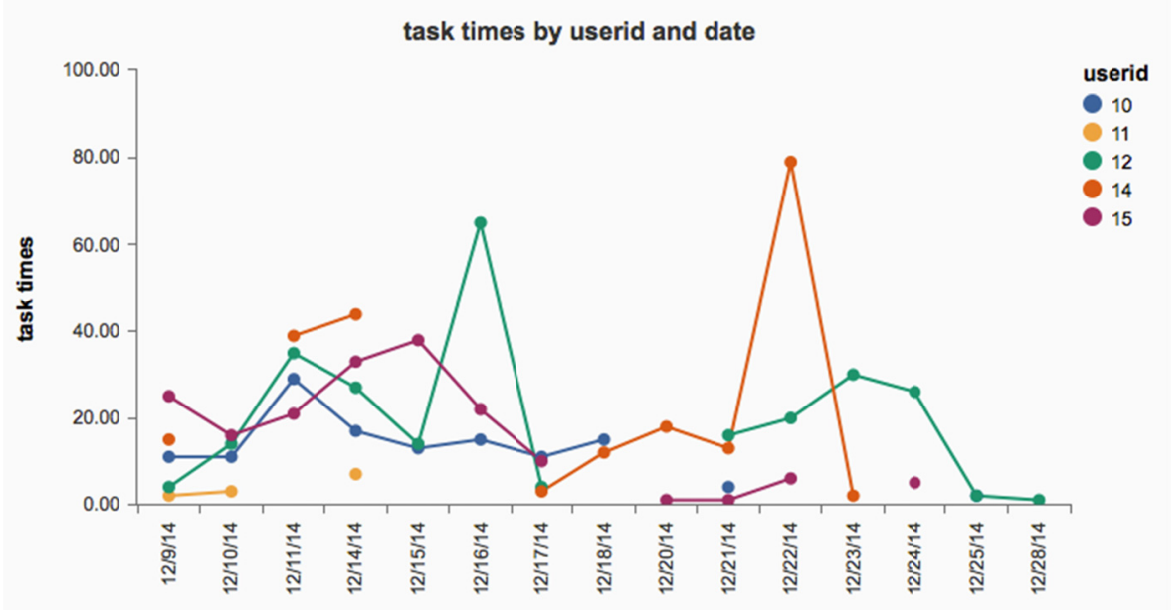

Figure 16. User12 was born in 1987

Users 14 and 15 play and love video games. (HR performance chart)

\subsubsection{Game Experience}

The survey have resulted that 55 percent of the employees are playing video games. Playing video games have a positive effect in being active on a gamified system (see Figures 15 and 16).

\subsubsection{Familiarity with Gamification Concept}

As the results have indicated, most of the employees have agreed on being familiar with germination and believing on its positive impact. The performance chart (see Figure 14) shows that employees familiar with the concept are more active than others.

Moreover, the study results, about familiarity with Gamification concept and believing of the positive impact that Gamification has on the employees' performance, agrees with what Meder, Plumbaum, \& Hopfgartner (2013) concluded in their study.

Furthermore, the age factor, which indicated that the younger that the employees is the more active he would be in the gamified system; moreover, the factor that indicates having game experience will increase using the gamified system, prove what Kumar (2013) wrote on his paper, "a new generation that has grown up playing online and video games".

\subsection{Ethical Related Factors}

Even though it wasn't directly experienced through "The Lord of ABANA" application case, it is clearly evident and observed that manipulation is easily possible through Gamification. Therefore, making employees work over time in general and daily tasks is considered to be unethical and inefficient. Moreover, making employees perform tasks that are not related to them is also unethical and insufficient. Other possible unethical manipulation can harm and decrease the Gamification efficiency and purpose.

Furthermore, previous studies (Schacht \& Schacht, 2012) have noted the ethical issues related to Gamification and how they can reduce the positive impact of Gamification.

Concluding, the resulted factors are utilized to logically express the following framework (Figure 17). The proposed framework identifies the factors that should be taken into consideration when studying or developing a gamified system with the aim of enhancing employees' performance. 


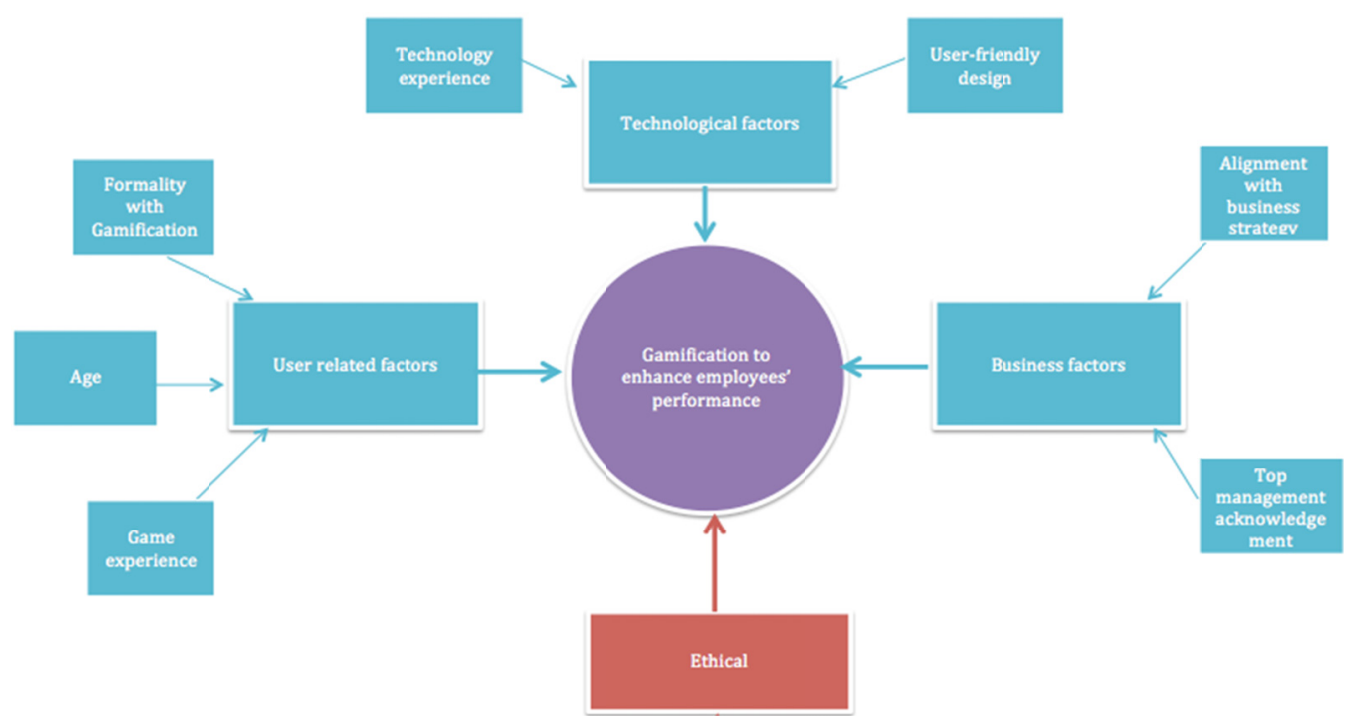

Figure 17. Gamification to enhance employees' performance framework

Finally, the factors that have been found and expressed in the framework do not have to be met all to achieve the goal of Gamification, for example: if the gamified application is not one hundred percent aligned with the business strategy, being one hundred percent top management involved and engaged can cover the weakness of the alignment, as ABANA's case have proved.

\section{Future Work}

It is true that this framework have only been resulted from one case study from a private sector in Saudi Arabia, but it is strongly recommended to apply and utilize it to study other gamified systems either in Saudi Arabia or internationally. One of the greatest gamified system that can be studied using the proposed framework is the application developed and utilized by Ministry of Commerce to enhance their employees' performance, which have resulted a magnificent results as the Minister of Commerce, Dr. Tawfiq Al- Rabie'a announced in his Twitter account.

\section{Conclusion}

Gamification role has been acknowledged in different fields as new trend. Moreover, a lot of studies and applications have emphasized its role in engaging with users. Unfortunately, there is no study that prove Gamification role in employees' performance enhancement completely or propose a clear framework that can be used to measure its effect in enhancing employees' performance.

Therefore, this study proposes a framework to help practitioners and researchers take into consideration when studying or developing a gamified system with the aim of enhancing employees' performance. These factors include, business, technological, user, and ethics related factors.

\section{References}

Alaa, A., Gary, W., \& Ashok, R. (2014). Gamification to improve adherence to diabeteic treatment in Saudi Arabia.

Alfursan Online. (n.d.). Retrieved December 2, 2014, from https://alfursan.saudiairlines.com/

Alkwai, L., Alkheibary, A., \& Almoaythir, A. (2014). Gamification in Arabic Interactive Educational Applications: Cultural and Language Considerations in Motivational Affordances of Design Elements. INTED2014 Proceedings, 4545-4556.

AlRouqi, H., \& Al-Khalifa, H. S. (2014, April). Making Arabic PDF books accessible using gamification. In Proceedings of the 11th Web for All Conference (p. 28). ACM. http://dx.doi.org/10.1145/2596695.2596712

Blohm, I., \& Leimeister, J. M. (2013). Design of IT-Based Enhancing Services for Motivational Support and Behavioral Change.

Burke, B. (2014, April 4). Gartner Redefines Gamification. Retrieved December 1, 2014, from http://blogs.gartner.com/brian_burke/2014/04/04/gartner-redefines-gamification/

Deterding, S., Dixon, D., Khaled, R., \& Nacke, L. (2011, September). From game design elements to gamefulness: defining gamification. In Proceedings of the 15th International Academic MindTrek Conference: Envisioning 
Future Media Environments (pp. 9-15). ACM. http://dx.doi.org/10.1145/2181037.2181040

Fu, Y. C. (2011). The Game of Life: Designing a Gamification System to Increase Current Volunteer Participation and Retention in Volunteer-based Nonprofit Organizations.

Gamified Labs. (2012, January 1). Retrieved December 2, 2014, from http://gamifiedlabs.com/

Gamifiers, T. (2013, January 1). The Gamifiers. Retrieved December 2, 2014, from http://www.thegamifiers.com/

Hall, M., Glanz, S., Caton, S., \& Weinhardt, C. (2013, September). Measuring Your Best You: A Gamification Framework for Well-Being Measurement. In Cloud and Green Computing (CGC), 2013 Third International Conference on (pp. 277-282). IEEE. http://dx.doi.org/10.1109/cgc.2013.51

Hamari, J., Koivisto, J., \& Sarsa, H. (2014, January). Does Gamification Work?--A Literature Review of Empirical Studies on Gamification. In System Sciences (HICSS), 2014 47th Hawaii International Conference on (p p. 3025-3034). IEEE.

Hense, J., Klevers, M., Sailer, M., Horenburg, T., Mandl, H., \& Günthner, W. (2014). Using gamification to enhance staff motivation in logistics. In Frontiers in Gaming Simulation (pp. 206-213). Springer International Publishing. http://dx.doi.org/10.1007/978-3-319-04954-0_24

Herzig, P., Ameling, M., \& Schill, A. (2012, August). A Generic Platform for Enterprise Gamification. In Software Architecture (WICSA) and European Conference on Software Architecture (ECSA), 2012 Joint Working IEEE/IFIP Conference on (pp. 219-223). IEEE. http://dx.doi.org/10.1109/wicsa-ecsa.212.33

Kompaso, S. M., \& Sridevi, M. S. (2010). Employee engagement: The key to improving performance. International Journal of Business and Management, 5(12), 89. http://dx.doi.org/10.5539/ijbm.v5n12p89

Kumar, J. (2013). Gamification at work: designing engaging business software (pp. 528-537). Springer Berlin Heidelberg. http://dx.doi.org/10.1007/978-3-642-39241-2_58

Li, C. (2014). Evaluation of a Theoretical Model for Gamification in Workplace IS context.

Llagostera, E. (2012). On gamification and persuasion. SB Games, Brasilia, Brazil, November 2-4, 12-21.

Maan, J. (2013). Social Business Transformation through Gamification. arXiv preprint arXiv:1309.7063.

Meder, M., Plumbaum, T., \& Hopfgartner, F. (2013, December). Perceived and actual role of gamification principles. In Proceedings of the 2013 IEEE/ACM 6th International Conference on Utility and Cloud Computing (pp. 488-493). IEEE Computer Society. http://dx.doi.org/10.1109/UCC.2013.95

Ministry of Labor. (2011, June 11). Nitaqat Video. Retrieved December 2, 2014, from http://www.youtube.com/watch?v=1Z-MJuQRtes

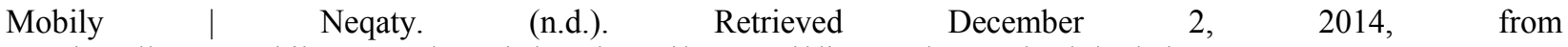
http://www.mobily.com.sa/portalu/wps/portal/personal/discover/neqaty/!ut/p/a1/pdBNC4

Morford, Z. H., Witts, B. N., Killingsworth, K. J., \& Alavosius, M. P. (2014). Gamification: The Intersection between Behavior Analysis and Game Design Technologies. The Behavior Analyst, 37(1), 25-40. http://dx.doi.org/10.1007/s40614-014-0006-1

Naseem, A., Sheikh, S. E., \& Malik, K. P. (2011). Impact of employee satisfaction on success of organization: relation between customer experience and employee satisfaction. International journal of multidisciplinary sciences and engineering, 2(5), 41-46.

Nicholson, S. (2012). A user-centered theoretical framework for meaningful gamification. Games + Learning + Society, $8,1$.

Oprescu, F., Jones, C., \& Katsikitis, M. (2014). I PLAY AT WORK - ten principles for transforming work processes through gamification. Frontiers in psychology, 5. http://dx.doi.org/10.3389/fpsyg.2014.00014

Otake, K., Sumita, R., Oka, M., Shinozawa, Y., Uetake, T., \& Sakurai, A. (2014). A Proposal of a Support System for Motivation Improvement Using Gamification. In Social Computing and Social Media (pp. 571-580). Springer International Pu blishing. http://dx.doi.org/10.1007/978-3-319-07632-4_54

Rampoldi-Hnilo, L., \& Snyder, M. (2013). The Business Love Triangle-Smartphones, Gamification, and Social Collaboration. In Human-Computer Interaction. Applications and Services (pp. 309-315). Springer Berlin Heidelberg. http://dx.doi.org/10.1007/978-3-642-39262-7_35

Reporter, A. (2013, June 10). Gamification coming to the Middle East -. Retrieved December 2, 2014, from http://www.arabiangazette.com/gamification-coming-middle-east-20130610/

Rughiniş, R. (2013). Work and Gameplay in the Transparent 'Magic Circle'of Gamification. In Design, User Experience, and Usability. Health, Learning, Playing, Cultural, and Cross-Cultural User Experience (pp. 577-586). Springer Berlin Heidelberg. 
SAP Lumira. (2012, Oct). Ignite Your Creative Ideas with Fast and Engaging Data Discovery. http://www.sap.com/bin/sapcom/en_us/downloadasset.2012-10-oct-25-07.ignite-your-creative-ideas-with-fast-a nd-engaging-data-discovery-pdf.html. SAP.

SAP Lumira. (2013, Feb 12). Lumira (formerly known as SAP Visual Intelligence) - Fast Relevent and intiuitive [Video file]. Retrieved from http://www.youtube.com/watch?v=31xPOd-1J5s

SAP Lumira. (2013, June). SAP Lumira V1.0.11 User Guide. http://help.sap.com/businessobject/product_guides/vi01/en/vi1_0_11_user_en.pdf. SAP.

Saudi Arabia's Nitaqat scheme stunts private sector growth prospects. (2014, March 12). Retrieved December 2, 2014,

from http://news.riskadvisory.net/index.php/2014/03/saudi-arabias-nitaqat-scheme-stunts-private-sector-growth-pros pects/

Schacht, M., \& Schacht, S. (2012). Start the Game: Increasing User Experience of Enterprise Systems Following a Gamification Mechanism. In Software for People (pp. 181-199). Springer Berlin Heidelberg. http://dx.doi.org/10.1007/978-3-642-31371-4_11

STC - What is Qitaf. (n.d.). Retrieved December 2, 2014, from http://www.stc.com.sa/wps/wcm/connect/english/loyaltyPrograms/qitaf/whatisqitaf

The Sephora Card program. (n.d.). Retrieved December 2, 2014, from http://loyalty.sephora-me.com/me_avantage

Webb, E. N. (2013). Gamification: When It Works, When It Doesn't. In Design, User Experience, and Usability. Health, Learning, Playing, Cultural, and Cross-Cultural User Experience (pp. 608-614). Springer Berlin Heidelberg. http://dx.doi.org/10.1007/978-3-642-39262-7_36

Webb, E. N., \& Cantú, A. (2013). Building Internal Enthusiasm for Gamification in Your Organization. In Human-Computer Interaction. Applications and Services (pp. 316-322). Springer Berlin Heidelberg. http://dx.doi.org/10.1007/978-3-642-39241-2_67

Werbach, K. (2014). (Re) Defining Gamification: A Process Approach. In Persuasive Technology (pp. 266-272). Springer International Publishing. http://dx.doi.org/10.1007/978-3-319-07127-5_23

Werbach, K., \& Dan H. (2012). For the win: How game thinking can revolutionize your business. Wharton Digital Press.

Xu, Y. (2011). Literature review on web application gamification and analytics. Honolulu, HI, 11-05.

\section{Appendicies}

Appendix A. The Distributed Survey

The Survey that was sent to employees' emails contained of the following parts:

- The Demographic questions including:

○ Name (optional): filling a textbox.

- Employee ID (optional): filling a textbox.

○ Department (mandatory): choosing from a list.

- Gender (mandatory): choosing wither male or female.

- Age (mandatory): choosing from a list, where its values have been written based on five-year age categorization (20-24, 25-29, 30-34, 35-39, >39).

- Game experience, where a Five-Point Likert scale question has been used which is, do you play video games? Moreover, another question have been asked regarding the average time the participants spend playing video game.

- A brief explanation about Gamification concept have been provided followed by another Five-Point Likert scale questions that discuss, the familiarity with Gamification concept, Gamification and motivation, and work environment, to include the following questions:

- "I am familiar with the Gamification concept".

○ "I think this kind of apps can motivate people".

○ "I find our work environment friendly more than being formal".

○ "I find our work environment routinely and boring". 